\title{
Trabecular bone score (TBS) as a noninvasive and complementary tool for clinical diagnosis of bone structure in endocrine disorders
}

\author{
Jowita Halupczok-Żyła, Łukasz Gojny, Marek Bolanowski \\ Department and Clinic of Endocrinology, Diabetes, and Isotope Therapy, Wrocław Medical University, Wrocław, Poland
}

\begin{abstract}
Trabecular bone score (TBS) index has recently been obtained as a result of textural greyscale analysis of DXA images. Because it enables the assessment of bone microarchitectural texture, TBS may be useful in evaluating bone quality. This study explores the current knowledge of the use of TBS in patients with endocrine disorders with co-occurring bone structure changes. Currently, the clinical importance TBS was verified in terms of disorders of the growth hormone/insulin-like growth factor 1 (GH/IGF-I) axis, glucocorticoid excess, thyroid and parathyroid disease, as well as in diabetes mellitus type 1 and 2.

It has been clarified that patients suffering from various endocrinopathies are a group in which TBS should be used routinely because it correlates with clinical factors and may improve patient management in various endocrine disorders. (Endokrynol Pol 2019; 70 (4): 350-356)

Key words: osteoporosis; fractures; bone quality
\end{abstract}

\section{Introduction}

\section{Osteoporosis, fragility fractures, and risk} assessment tools

Osteoporosis is considered to be the most common of all bone diseases [1], affecting over 200 million people worldwide. It is characterised by bone microarchitectural abnormalities resulting in altered bone quality and decreased bone strength. Altogether, these changes result in an increased risk of fractures, totalling as much as 9 million occurrences per year [2-4]. Unfortunately, these cause significant morbidity and mortality; hip fractures alone are believed to be linked with more than 700,000 deaths [5]. Therefore, it is very important to identify individuals capable of fragility fractures in the near future, in order to initiate proper treatment and minimise the risk.

Dual-energy X-ray absorptiometry (DXA) is a key tool used in fracture risk assessment. With its use, bone mineral density (BMD) can be measured. BMD is the reference standard for diagnosis of osteoporosis, as well as the fracture risk stratification [5]. It has been proven that each standard deviation (SD) decrease in BMD results in a 1.4-fold to 2.6-fold increase in the risk of fracture [6]. On the other hand, most individuals with fragility fractures show normal BMD values or osteopaenia, which complicates the comprehensive diagnosis. The main reason for that is that DXA gives only information regarding bone density, without assesing the bone microarchitecture. Impaired architecture, which is independent of BMD, is associated with greater risk of fracture [7]. Therefore, it is essential to identify other skeletal and extra skeletal risk factors that would contribute to better selection of patients who request immediate treatment [8-10].

There are several easily assessable clinical risk factors, including age, smoking, alcohol intake, glucocorticoid use, as well as previous fragility fracture or parental history of hip fracture, which have an impact on fracture risk independent of measured BMD. This has resulted in the development of additional assessment tools, e.g. FRAX. FRAX can be used to establish the 10-year probability of hip and major osteoporotic fracture (MOF), validated in independent cohort studies [11-14].

Additionally, there are also skeletal parameters, such as bone geometry, microarchitecture, microdamage, rate of mineralisation, and rate of bone turnover, which, as well as BMD, contribute to bone strength and risk of fracture $[1,8,15,16]$. For example, high-resolution peripheral quantitative computed tomography was designed to assess the bone microstructure, leading to the ability to differentiate between women with and 
without fragility fractures [12]. This is, however, used only as a research tool.

Recently, the trabecular bone score (TBS) index has been introduced as a result of textural greyscale analysis of DXA images. As it enables the assessment of bone microarchitectural texture, TBS may be useful in evaluating bone quality. Going further, it may be an independent and additional instrument for assessment of bone, as well as other clinical risk factors and FRAX $[17,18]$.

\section{Trabecular bone score}

\section{Definition}

Trabecular bone score is a textural index that is a result of computed evaluation of pixel grey-level variations in lumbar spine DXA images. Therefore, it provides an indirect index of bone microarchitecture. As a result of a computed score of the two-dimensional plane of three-dimensional bone structure, obtained from DXA imaging, TBS can be used as an index of the bone microstructure state. It is strongly connected with $3 \mathrm{D}$ bone characteristics such as the trabecular number, the trabecular separation, and the connectivity density $[2$, $4,17,19,20]$.

Because TBS uses previously obtained DXA images, it enabled the generation of longitudinal data concerning cross-sectional and clinical studies. This also allows direct comparison with areal BMD (aBMD) and application to existing datasets. As such, there is now strong evidence that TBS can differentiate between two three-dimensional (3D) microarchitectures that exhibit the same bone density but different trabecular characteristics.

\section{TBS evaluation results}

In clinical practice, the TBS is calculated in a second by currently commercially available software. The software can be applied prospectively or retrospectively to any standard DXA images obtained with the use of modern fan beam densitometers.

An elevated TBS appears when there is a strong, fracture-resistant bone microarchitecture found. A low TBS indicates weak bone, prone to fractures. It has been shown that low TBS is associated with fewer, widely distributed, and poorly connected trabeculae, while high TBS values correlate with stronger trabecular structure.

Trabecular bone score cut-off points classifying normal and abnormal TBS values have not yet been defined. The only available TBS range is one that has been proposed for postmenopausal women [21-23].

The following normal range for TBS values in postmenopausal women has been proposed: TBS
$>1.350$ units is considered to be normal; TBS between 1.200 and 1.350 is connected with partially degraded microarchitecture; and TBS $<1.200$ should define degraded microarchitecture [23]. The existing literature indicates that low lumbar spine TBS is associated with a history of fracture and the incidence of new fracture. The effect is largely independent of BMD and is of sufficient magnitude to enhance risk stratification with BMD [2].

\section{TBS and bone microarchitecture}

It has been shown that TBS strongly correlates positively with trabecular bone volume (BV) to tissue volume (TV) ratio (BV/TV). It also correlates with the number of trabeculae, their stiffness, and their connectivity. TBS correlates negatively with intra-trabecular space and structure model index [24]. Another ex vivo study confirmed strong negative associations between TBS and structure model index, as well as positive correlations with number of trabeculae and $\mathrm{BV} / \mathrm{TV}$ ratio. These correlations were adjusted according to one's age, sex, past vertebral fracture, and LS-BMD [20]. What is more, concerning ex vivo studies, significant correlations between TBS and bone volume fraction were found in trabecular spacing and trabecular number in cadaveric vertebral, femoral neck, and distal radius samples.[25] Other researchers found that TBS correlates with various microarchitectural bone parameters in patients with idiopathic osteoporosis [20]. To sum up, ex vivo studies stated that TBS provides an indirect measure of bone microstructure characteristics [2, 14, 17, 19, 20, 26, 27].

Several in vivo studies that compared TBS with central quantitative computed tomography found correlations between TBS and lumbar spine trabecular volumetric BMD, as well as trabecular and cortical parameters of the femoral neck and hip. This was, however, significant only without adjustments for ages, BMI, BMD, and ethnicity $[5,28]$. This means that TBS may not fully capture all aspects of bone microstructure, which can be now assessed by high-resolution imaging procedures [12].

\section{TBS limitations}

Like other clinical management tools, TBS is characterised by several limitations, including clinical and technical aspects. It has been shown, for example, that as the DXA image resolution degrades, so the TBS value increases [24]. It has also been indicated that the thickness of soft tissue underlying the spine can result in decreased TBS values [29]. What is more, a dependence of TBS on BMI, body composition, and age has been found [30,31]. The excessive amount of abdominal soft tissue can also be a reason for overestimated TBS values [32]. 


\section{Trabecular bone score in endocrine disorders}

\section{Disorders of the growth hormone/insulin-like growth factor 1 (GH/IGF-I) axis}

Acromegaly is a rare chronic disease caused by excess secretion of $\mathrm{GH}$, most often from an adenoma of the pituitary gland [33]. The condition is considered to be associated with an increased risk of fragility fractures, even when the bone mineral density (BMD) is within normal range. This indicates that GH/IGF-I overproduction may influence the bone microarchitecture [34]. Hong et al. suggested TBS as a useful tool in the assessment of skeletal fragility in acromegaly. The results of the study showed that lumbar spine TBS was lower in acromegaly patients than in controls for both men and women $(1.345 \pm 0.121$ vs. $1.427 \pm 0.087, \mathrm{p}=0.005$ in men; $1.356 \pm 0.082$ vs. $1.431 \pm 0.071, \mathrm{p}=0.001$ in women). However, BMD values at all sites were similar. Hypogonadal acromegaly patients had lower TBS values compared with male and female controls ( $1.333 \pm 0.103$ vs. $1.419 \pm 0.098, \mathrm{p}=0.031 ; 1.339 \pm 0.086$ vs. $1.415 \pm 0.060, \mathrm{p}=0.001$; respectively). To exclude the hypogonadal effect, the authors also compared eugonadal patients with the control group. Lumbar spine TBS was significantly lower only in eugonadal women [33]. In another study, researchers investigated how the treatment of acromegaly affects TBS results, and observed a significant decrease in TBS value one year postoperatively in a subgroup of 38 subjects, whereas BMD values increased by $3.2( \pm 4.9) \%(\mathrm{p}<0.01)$. No correlation was shown between the change in TBS and the following variables: GH, IGF-I, BMI, bone markers, 25(OH)D, BMD LS or change in BMD LS, and bone markers or IGF-I. These results may support the hypothesis that persisting increased risk of fracture is caused by changes occurring in trabecular bone architecture. On the other hand, the observed decrease of TBS may be attributed to the underestimation of TBS values due to fat accumulation mainly in central depots as a result of the treatment of acromegaly [35]. Valassi et al. investigated the relationship between TBS, spine volumetric $B M D$ (LS vBMD) measured by quantitative computed tomography (QCT), and fat depots in acromegaly and healthy controls. Both LS vBMD and TBS were inversely correlated with epicardial adipose tissue $(E A T)$ in the acromegaly group $(\mathrm{q}=-0.69, \mathrm{p}=0.001$; $q=-0.56, p=0.015$, respectively).

Although growth hormone deficiency (GHD) is also associated with alteration of bone architecture, research concerning the usage of TBS in these patients is still limited. The first prospective study assessed the effect of two-year growth hormone replacement therapy on TBS in a subgroup of 32 subjects with GHD. The highest increase in TBS value was observed at the level of vertebra L4 (4\%, $\mathrm{p}=0.02)$ after two-year recombinant human $\mathrm{GH}(\mathrm{rhGH})$ treatment. Lumbar spine and femur BMD were recorded in the whole group of 147 GHD patients (age 35.1 years, 84 males/63 females, 43 cases of childhood onset GHD/104 cases of adult onset GHD) and increased significantly during a two-year period of treatment (14\% and 7\% increase, respectively) [36]. The second study on a group of 18 adult GHD patients (mean age, $37.39 \pm 12.42$ years) demonstrated that over a seven-year treatment time TBS remained at the baseline level (no statistically significant differences) whereas lumbar spine BMD increased $(p=0.01)$ [37].

\section{Glucocorticoids and TBS}

It is well established that both exogenous and endogenous glucocorticoid excess is associated with increased fracture risk often independently of BMD [38-40]. Eller-Vainicher et al. demonstrated on a cohort of 102 subjects with adrenal incidentaloma (AI) that patients with subclinical hypercortisolaemia (SH) had lower LS-BMD, FT-BMD, and TBS than patients without SH and controls. Additionally, TBS values were lower in subjects without $\mathrm{SH}$ compared with the control group. Logistic regression analysis revealed that low TBS alone and the combination of low TBS and low LS-BMD were both associated with the presence of vertebral fractures. No such association was found for low LS-BMD alone. Accordingly, the combination of normal TBS and normal LS-BMD was associated with the absence of vertebral fractures. Finally, TBS predicted the occurrence of a new fracture in a subgroup of 40 subjects followed for 24 months independently of LS-BMD, BMI, and age [38]. A study on 51 Caucasian women with AI also showed TBS impairment in comparison with normal TBS values for age, while no differences were found for BMD. Hypogonadism and hypercortisolism presented a negative effect on TBS but not on BMD [41]. Another study concerning the risk factors for fracture in endogenous Cushing's syndrome (CS) patients revealed that the only predictor of low traumatic fracture, after adjustment for age, gender, BMD, and TBS was the level of free cortisol in 24-hour urine sample. However, the study sample had low TBS, and the bone microarchitecture was classified as mainly degraded $(49.5 \%)$ or partially degraded (34\%) according to the previously described definitions for postmenopausal women [42]. A recent cross-sectional study on a group of 608 women (mean age 65.5 years) by Kuehner et al. investigated the relationship between salivary cortisol circadian rhythm and TBS. The subjects in the highest tertile of $8 \mathrm{PM}$ salivary cortisol (sc-8PM) had lower TBS values than the subjects in the lowest tertile (1.27 vs. 1.29; $\mathrm{p}=0.02)$. Radiologic VFx prevalence was associated with sc-8PM and TBS independently of each other and of other risk 
factors including age and lumbar spine BMD. These results support the findings from previous studies on patients with adrenal incidentaloma [39].

There are few studies attempting to examine the influence of treatment with glucocorticoids on TBS. Paggiosi et al. studied the ability of LS-BMD, TBS, and LS-BMD combined with TBS (LS-BMD+TBS) to discriminate between glucocorticoid-treated women (prednisolone $\geq 5 \mathrm{mg} /$ day or equivalent for $>3$ months), women with recent fractures $(\leq 6$ months since fracture of the distal forearm, proximal humerus, vertebra or proximal femur), and glucocorticoid-naive, healthy women without fractures. The essential conclusions of the research are that TBS was able to discriminate between women with recent fractures and healthy women without fractures, and also between glucocorticoid-treated women and healthy, glucocorticoid-naive women, independently of LS-BMD [40]. Similarly, in a study on 1520 men and women aged 40 years or more, TBS was reported to be decreased in GC-treated patients compared with matched controls (1.267 vs. 1.298, p < 0.001), whereas there was no difference in BMD at any site. The same results were obtained when the sample was divided according to sex. GC patients with fracture showed significantly lower TBS values than subjects without fracture. An association between TBS and the presence of fracture was also observed [43]. The studies on patients with systemic sclerosis and rheumatoid arthritis demonstrated that TBS was significantly lower in subjects treated with GC compared with non-treated subjects and was also lower in patients with fractures compared with those without fractures [44, 45].

\section{Primary hyperparathyroidism}

Primary hyperparathyroidism (PHPT) is known to be associated with cortical bone loss and increased fracture risk. A prospective study on a group $92 \mathrm{PHPT}$ patients (74 females, age 62.1 \pm 9.7 years) and 98 control subjects assessed the association of vertebral fracture and TBS. PHPT patients had lower TBS and higher VFx prevalence $(43.5 \%)$ than the control group. The logistic regression analysis showed that TBS was associated with VFx (odds ratio 1.4, 95\% CI: 1.1-1.9, $\mathrm{p}=0.02$ ) regardless of LS-BMD, age, BMI, and gender. In a subgroup of 20 surgically treated patients at a two-year follow-up, TBS increased significantly, while in patients who were treated conservatively TBS decreased significantly in those with incident VFx as compared to those without [46]. In accordance with these findings, Romagnoli et al. showed that mean TBS values were significantly lower in PHPT than in controls $(1.19 \pm 0.10,1.24 \pm 0.09$; respectively, $\mathrm{p}=0.01$ ) and that TBS was also decreased in PHPT subjects with vertebral fractures in comparison with those without fracture $(1.14 \pm 0.10,1.24 \pm 0.09$, respectively, $\mathrm{p}=0.001)$. It was also concluded that the presence of vertebral fractures in PHPT patients was independently associated with the reduction of TBS $(\mathrm{OR}=0.003,95 \% \mathrm{CI}: 0-0.534, \mathrm{p}=0.028)$ and the increase of years since menopause $(\mathrm{OR}=1.076,95 \% \mathrm{CI}$ : $1.017-1.139, \mathrm{p}=0.011)$, but not with age, the increase of BMI, and the reduction of LS-BMD [47]. In other study, the authors evaluated differences in TBS in asymptomatic hyperparathyroidism [24 normocalcaemic hyperparathyroidism (NHPT) and 15 hypercalcaemic hyperparathyroidism (HHPT)]. TBS and BMD (all sites) were similar in both subgroups. Asymptomatic HPT subjects were characterised by significantly higher parathyroid hormone (PTH) and significantly lower TBS and areal BMD at all sites. A significant negative relationship between TBS and PTH was found in asymptomatic HPT patients, after adjustment for age, sex, and BMI. These results may reflect a possible role of PTH in bone microarchitecture alteration [48]. Silva et al. evaluated TBS in relation to HRpQCT measurements of volumetric bone density, skeletal microarchitecture, and bone stiffness in a cross-sectional study on 22 postmenopausal women with PHPT. TBS values correlated with whole bone stiffness and all HRpQCT indices, except for trabecular thickness and trabecular stiffness at the radius. At the tibia, correlations were noted between TBS and volumetric densities, cortical thickness, trabecular bone volume, and whole bone stiffness. After adjustment for body weight, TBS was correlated with all indices of trabecular microarchitecture except trabecular thickness [49].

Other authors focused on the relationship between vitamin D and TBS in PHPT patients. The first study revealed no differences in TBS values between the three following groups: vitamin D level $<20 \mathrm{ng} / \mathrm{mL}, 20-29$ $\mathrm{ng} / \mathrm{mL}$, and $\geq 30 \mathrm{ng} / \mathrm{mL}$ even after adjusting for age, sex, weight, and GFR [50]. The second study was designed as an investigator-initiated, double-blind, randomised, placebo-controlled, parallel-group trial and comprised a study group of 46 PHPT patients (35 women, 11 men; mean age 58 years). The patients were supplemented with $70 \mu \mathrm{g}(2800 \mathrm{IU})$ of cholecalciferol or placebo for 26 weeks before parathyroidectomy (PTX) and 26 weeks following PTX. TBS did not change in response to vitamin $\mathrm{D}$ treatment but improved significantly after PTX [51].

\section{Thyroid diseases}

In patients with higher fT4 levels within the normal reference values deterioration of trabecular microarchitecture was observed. This, however, particularly affected postmenopausal, healthy euthyroid women. The relationship between thyroid hormone levels and 
bone parameters revealed negative association between TBS of L1-4 and fT4 levels $(\beta=-0.11, \mathrm{p}=0.002)$ [52]. The comparative study concerning pre- and postmenopausal patients with differentiated thyroid carcinoma (DTC) receiving long-term TSH suppressive therapy (TST) revealed that postmenopausal women with DTC receiving TST had lover TBS, compared to premenopausal patients. These TBS changes did not co-occur with BMD loss [53]. Similar results concerning TST in group of postmenopausal DTC patients were confirmed by other authors, also indicating that more than five years of TST resulted in lower lumbar spine TBS values compared to patients with therapy of less than three years $(1.335 \pm 0.092$ vs. $1.296 \pm 0.078$, $\mathrm{p}=0.015)$ [54].

Other studies based on a group of premenopausal women showed that Graves' Disease is in strong correlation with decreased TBS, whereas the BMD still did not differ between active the Graves' Disease group and the control group [55].

\section{Diabetes mellitus}

Patients with diabetes mellitus (type 1 and type 2) are predisposed to higher fracture risk [56]. When compared to controls, bone mineral density is decreased in type 1 diabetes mellitus (T1DM) and increased in type 2 diabetes mellitus (T2DM), which suggests that alterations in bone quality play an important role in the development of fragility fractures in this group of patients [56-58]. In a recent study, a cohort of T1DM patients with prevalent fractures showed a significantly lower TBS than T1DM patients without fractures $(1.309 \pm 0.125$ vs. $1.370 \pm 0.127, \mathrm{p}=0.04)$. Lower TBS and $\mathrm{HbA1c}$ were independently associated with the occurrence of fractures in T1DM subjects [57].

There are several available studies demonstrating that in patients with T2DM, TBS values are decreased and BMD values are increased when compared to non-diabetic subjects [58-61]. What is more, among T2DM patients, TBS seems to have higher values in subjects with good glycaemic control than in subjects with poor glycaemic control [58]. This is corroborated by another study, in which TBS was found to be negatively correlated with $\mathrm{HbA}_{1 \mathrm{c}^{\prime}}$ fasting plasma glucose, fasting insulin, and homeostasis model assessment — insulin resistance (HOMA-IR) [59]. These results show promise that TBS might be used to identify skeletal deterioration in T2DM patients in whom BMD only seems to be unsatisfactory [59]. A retrospective study on 169 Korean postmenopausal women with T2DM showed that significantly lower TBS $(\mathrm{p}=0.008)$ and higher TBS-adjusted FRAX scores were reported $(p=0.019)$ in the group with vertebral fractures (VFs) compared to the group without VFs. On the contrary, no significant dif- ferences were seen between the two groups in terms of BMD and original FRAX scores [60]. Finally, a large-scale study on 29,407 women (50 years old and above, 2356 of whom were diagnosed with diabetes) determined TBS as a BMD-independent predictor of fracture. TBS predicted fractures in patients with diabetes (adjusted hazard ratio $1.27,95 \% \mathrm{CI}: 1.10-1.46)$ and without diabetes (hazard ratio 1.31, 95\% CI: 1.24-1.38) [60].

\section{Conclusions}

Although TBS is a relatively young method, numerous studies confirm the importance of this technique in diagnostic and therapeutic procedures in patients with increased fracture risk. In this aspect, patients suffering from various endocrinopathies have become a group in which TBS should be used routinely, in combination with both aBMD and FRAX. The given clinical and scientific proof supporting the use of TBS, with its ability to be integrated in daily clinical practice, makes TBS an attractive, useful, and efficient clinical tool for physicians to improve patients' management in various endocrine disorders.

Because TBS holds promise as an emerging technology that could well become a useful clinical tool in the diagnosis of fracture risk assessment, every effort should be made to ensure that the results of these patients are developed and published. Further research and clarification of the role of TBS in additional specific disorders is ongoing.

\section{References}

1. Biver E, Durosier-Izart C, Chevalley T, et al. Evaluation of Radius Microstructure and Areal Bone Mineral Density Improves Fracture Prediction in Postmenopausal Women. J Bone Miner Res. 2018; 33(2): 328-337, doi: 10.1002/jbmr.3299, indexed in Pubmed: 28960489.

2. Shevroja E, Lamy O, Kohlmeier L, et al. Use of Trabecular Bone Score (TBS) as a Complementary Approach to Dual-energy X-ray Absorptiometry (DXA) for Fracture Risk Assessment in Clinical Practice. J Clin Densitom. 2017; 20: 334-45, doi: 10.1016/j.jocd.2017.06.019, indexed in Pubmed: 28734710

3. Ward RJ, Roberts CC, Bencardino JT, et al. Expert Panel on Musculoskeletal Imaging. ACR Appropriateness Criteria Osteoporosis and Bone Mineral Density. J Am Coll Radiol. 2017; 14(5S): S189-S202, doi: 10.1016/j. jacr.2017.02.018, indexed in Pubmed: 28473075.

4. Oei L, Koromani F, Rivadeneira F, et al. Quantitative imaging methods in osteoporosis. Quant Imaging Med Surg. 2016; 6(6): 680-698, doi: 10.21037/qims.2016.12.13, indexed in Pubmed: 28090446.

5. Martineau P, Leslie WD. Trabecular bone score (TBS): Method and applications. Bone. 2017; 104: 66-72, doi: 10.1016/j.bone.2017.01.035, indexed in Pubmed: 28159710.

6. Silva BC, Leslie WD. Trabecular Bone Score: A New DXA-Derived Measurement for Fracture Risk Assessment. Endocrinol Metab Clin North Am. 2017; 46(1): 153-180, doi: 10.1016/j.ecl.2016.09.005, indexed in Pubmed: 28131130.

7. Seeman E, Delmas PD. Bone quality - the material and structural basis of bone strength and fragility. N Engl J Med. 2006; 354(21): 2250-2261, doi: 10.1056/NEJMra053077, indexed in Pubmed: 16723616.

8. Leslie WD, Majumdar SR, Morin SN, et al. Change in Trabecular Bone Score (TBS) With Antiresorptive Therapy Does Not Predict Fracture in Women: The Manitoba BMD Cohort. J Bone Miner Res. 2017; 32(3): 618-623, doi: 10.1002/jbmr.3054, indexed in Pubmed: 27933656.

9. Martineau P, Leslie WD, Johansson H, et al. Clinical Utility of Using Lumbar Spine Trabecular Bone Score to Adjust Fracture Probability: 
The Manitoba BMD Cohort. J Bone Miner Res. 2017; 32(7): 1568-1574, doi: 10.1002/jbmr.3124, indexed in Pubmed: 28276598.

10. Battista C, Chiodini I, Muscarella S, et al. Spinal volumetric trabecula bone mass in acromegalic patients: a longitudinal study. Clin Endocrinol (Oxf). 2009; 70(3): 378-382, doi: 10.1111/j.1365-2265.2008.03322.x, indexed in Pubmed: 18616713 .

11. Couraud G, Souffir C, Gaigneux E, et al. Adjusting FRAX ${ }^{\circledR}$ on TBS for identification of subjects at high risk of fractures. Bone. 2017; 101 214-218, doi: 10.1016/j.bone.2017.05.005, indexed in Pubmed: 28479495

12. Silva BC, Bilezikian JP. Trabecular bone score: perspectives of an imaging technology coming of age. Arq Bras Endocrinol Metabol. 2014; 58(5): 493-503, indexed in Pubmed: 25166040.

13. McCloskey EV, Odén A, Harvey NC, et al. Adjusting fracture probability by trabecular bone score. Calcif Tissue Int. 2015; 96(6): 500-509, doi: 10.1007/s00223-015-9980-x, indexed in Pubmed: 25796374

14. Leslie WD, Aubry-Rozier B, Lix LM, et al. Spine bone texture assessed by trabecular bone score (TBS) predicts osteoporotic fractures in men: the Manitoba Bone Density Program. Bone. 2014; 67: 10-14, doi: 10.1016/j bone.2014.06.034, indexed in Pubmed: 24998455.

15. Messina C, Poloni A, Chianca V, et al. Increasing soft tissue thicknes does not affect trabecular bone score reproducibility: a phantom study. Endocrine. 2018; 61(2): 336-342, doi: 10.1007/s12020-018-1647-8, indexed in Pubmed: 29948934.

16. Mazziotti G, Biagioli E, Maffezzoni F, et al. Bone turnover, bone minera density, and fracture risk in acromegaly: a meta-analysis. J Clin Endocrinol Metab. 2015; 100(2): 384-394, doi: 10.1210/jc.2014-2937, indexed in Pubmed: 25365312

17. Cortet B, Bousson V. TBS and bone strength. Bonekey Rep. 2016; 5: 792 , doi: 10.1038/bonekey.2016.19, indexed in Pubmed: 26962449.

18. Kim YS, Han JJ, Lee J, et al. The correlation between bone mineral density/trabecular bone score and body mass index, height, and weight. Osteoporos Sarcopenia. 2017; 3(2): 98-103, doi: 10.1016/j.afos.2017.02.001, indexed in Pubmed: 30775511.

19. Roux JP, Wegrzyn J, Boutroy S, et al. The predictive value of trabecular bone score (TBS) on whole lumbar vertebrae mechanics: an ex vivo study. Osteoporos Int. 2013; 24(9): 2455-2460, doi: 10.1007/s00198-013-2316-7, indexed in Pubmed: 23468074.

20. Muschitz C, Kocijan R, Haschka J, et al. TBS reflects trabecular microarchitecture in premenopausal women and men with idiopathic osteoporosis and low-traumatic fractures. Bone. 2015; 79: 259-266, doi: 10.1016/j. bone.2015.06.007, indexed in Pubmed: 26092650.

21. Ayoub ML, Maalouf G, Cortet B, et al. Trabecular Bone Score and Osteoporotic Fractures in Obese Postmenopausal Women. J Clin Densitom. 2016; 19(4): 544-545, doi: 10.1016/j.jocd.2016.03.004, indexed in Pubmed: 27067300.

22. De Mingo Dominguez ML, Guadalix Iglesias S, Martin-Arriscado Arroba C, et al. Low trabecular bone score in postmenopausal women with differentiated thyroid carcinoma after long-term TSH suppressive therapy. Endocrine. 2018; 62(1): 166-173, doi: 10.1007/s12020-018-1671-8, indexed in Pubmed: 30014437.

23. Silva BC, Leslie WD, Resch $\mathrm{H}$, et al. Trabecular bone score: a noninvasive analytical method based upon the DXA image. J Bone Miner Res. 2014; 29(3): 518-530, doi: 10.1002/jbmr.2176, indexed in Pubmed: 24443324.

24. Winzenrieth R, Michelet F, Hans D. Three-dimensional (3D) microarchitecture correlations with $2 \mathrm{D}$ projection image gray-level variation assessed by trabecular bone score using high-resolution computed tomographic acquisitions: effects of resolution and noise. J Clin Densitom. 2013; 16(3): 287-296, doi: 10.1016/j.jocd.2012.05.001, indexed in Pubmed: 22749406

25. Pothuaud L, Carceller P, Hans D. Correlations between grey-level variations in $2 \mathrm{D}$ projection images (TBS) and 3D microarchitecture: applications in the study of human trabecular bone microarchitecture. Bone. 2008; 42(4): 775-787, doi: 10.1016/j.bone.2007.11.018, indexed in Pubmed: 18234577.

26. Schousboe JT, Vo TN, Langsetmo L, et al. Osteoporotic Fractures in Men (MrOS) Study Research Group. Predictors of change of trabecular bone score (TBS) in older men: results from the Osteoporotic Fractures in Men (MrOS) Study. Osteoporos Int. 2018; 29(1): 49-59, doi: 10.1007/s00198-017-4273-z, indexed in Pubmed: 29090329.

27. Bousson V, Bergot C, Sutter B, et al. Scientific Committee of the Groupe de Recherche et d'Information sur les Ostéoporoses. Trabecular bone score (TBS): available knowledge, clinical relevance, and future prospects. Osteoporos Int. 2012; 23(5): 1489-1501, doi: 10.1007/s00198-011-1824-6, indexed in Pubmed: 22083541.

28. Martineau P, Silva BC, Leslie WD. Utility of trabecular bone score in the evaluation of osteoporosis. Curr Opin Endocrinol Diabetes Obes. 2017; 24(6): 402-410, doi: 10.1097/MED.0000000000000365, indexed in Pubmed: 28857846.

29. Amnuaywattakorn S, Sritara $C$, Utamakul $C$, et al Simulated in creased soft tissue thickness artefactually decreases trabecular bone score: a phantom study. BMC Musculoskelet Disord. 2016; 17: 17 , doi: 10.1186/s12891-016-0886-1, indexed in Pubmed: 26757709.
30. Schousboe JT, Vo TN, Langsetmo L, et al. Osteoporotic Fractures in Men (MrOS) Study Research Group. Association of Trabecular Bone Score (TBS) With Incident Clinical and Radiographic Vertebral Fractures Adjusted for Lumbar Spine BMD in Older Men: A Prospective Cohort Study. J Bone Miner Res. 2017; 32(7): 1554-1558, doi: 10.1002/jbmr.3130, indexed in Pubmed: 28300346.

31. Simonelli C, Leib E, Mossman N, et al. Creation of an age-adjusted, dual-energy X-ray absorptiometry-derived trabecular bone score curve for the lumbar spine in non-Hispanic US White women. J Clin Densitom. 2014; 17(2): 314-319, doi: 10.1016/j.jocd.2013.09.002, indexed in Pubmed: 24582086.

32. Kim JH, Choi HJ, Ku EJ, et al. Regional body fat depots differently affect bone microarchitecture in postmenopausal Korean women. Osteoporos Int. 2016; 27(3): 1161-1168, doi: 10.1007/s00198-015-3329-1, indexed in Pubmed: 26475286

33. Gromov AA, Il'In AP, Foerter-Barth U, et al. Effect of the passivating coating type, particle size, and storage time on oxidation and nitridation of aluminum powders. Combust Explos Shock Waves. 2006; 42: 177-84, doi: 10.1007/s00198-015-3344-2.

34. Valassi E, Crespo I, Malouf J, et al. Epicardial fat is a negative predictor of spine volumetric bone mineral density and trabecular bone score in acromegaly. Endocrine. 2016; 53(3): 860-864, doi: 10.1007/s12020-016-0945-2, indexed in Pubmed: 27055553.

35. Godang K, Olarescu NC, Bollerslev J, et al. Treatment of acromegaly increases BMD but reduces trabecular bone score: a longitudinal study. Eur J Endocrinol. 2016; 175(2): 155-164, doi: 10.1530/EJE-16-0340, indexed in Pubmed: 27220351.

36. Kužma M, Kužmová Z, Zelinková Z, et al. Impact of the growth hormone replacement on bone status in growth hormone deficient adults. Growth Horm IGF Res. 2014; 24(1): 22-28, doi: 10.1016/j.ghir.2013.12.001, indexed in Pubmed: 24382377.

37. Allo Miguel G, Serraclara Plá A, Partida Muñoz ML, et al. Seven years of follow up of trabecular bone score, bone mineral density, body composition and quality of life in adults with growth hormone deficiency treated with rhGH replacement in a single center. Ther Adv Endocrinol Metab. 2016; 7(3): 93-100, doi: 10.1177/2042018816643908, indexed in Pubmed: 27293538.

38. Eller-Vainicher C, Filopanti M, Palmieri S, et al. Bone quality, as measured by trabecular bone score, in patients with primary hyperparathyroidism. Eur J Endocrinol. 2013; 169(2): 155-162, doi: 10.1530/EJE-13-0305, indexed in Pubmed: 23682095.

39. Belaya ZE, Hans D, Rozhinskaya LY, et al. The risk factors for fracture and trabecular bone-score value in patients with endogenous Cushing's syndrome. Arch Osteoporos. 2015; 10: 44, doi: 10.1007/s11657-015-0244-1, indexed in Pubmed: 26608406.

40. Paggiosi MA, Peel NFA, Eastell R. The impact of glucocorticoid therapy on trabecular bone score in older women. Osteoporos Int 2015; 26(6): 1773-1780, doi: 10.1007/s00198-015-3078-1, indexed in Pubmed: 25743176

41. Rizou S, Chronopoulos E, Ballas M, et al. Clinical manifestations of osteoarthritis in osteoporotic and osteopenic postmenopausa women. J Musculoskelet Neuronal Interact. 2018; 18(2): 208-214, doi: 10.1007/s00198-013-2312-y, indexed in Pubmed: 29855443.

42. Gonzalez Rodriguez E, Lamy O, Stoll D, et al. High Evening Cortiso Level Is Associated With Low TBS and Increased Prevalent Vertebral Fractures: OsteoLaus Study. J Clin Endocrinol Metab. 2017; 102(7): 2628-2636, doi: 10.1210/jc.2016-3804, indexed in Pubmed: 28379565

43. Leib ES, Winzenrieth R. Bone status in glucocorticoid-treated men an women. Osteoporos Int. 2016; 27(1): 39-48, doi: 10.1007/s00198-015-3211-1, indexed in Pubmed: 26252975.

44. Koumakis E, Avouac J, Winzenrieth R, et al. Trabecular bone score in female patients with systemic sclerosis: comparison with rheumatoid arthritis and influence of glucocorticoid exposure. J Rheumatol. 2015; 42(2): 228-235, doi: 10.3899/jrheum.140752, indexed in Pubmed: 25448793.

45. Bréban S, Briot $K$, Kolta $S$, et al. Identification of rheumatoid arthriti patients with vertebral fractures using bone mineral density and trabecular bone score. J Clin Densitom. 2012; 15(3): 260-266, doi: 10.1016/j. jocd.2012.01.007, indexed in Pubmed: 22445857.

46. Eller-Vainicher C, Morelli V, Ulivieri FM, et al. Bone quality, as measured by trabecular bone score in patients with adrenal incidentalomas with and without subclinical hypercortisolism. J Bone Miner Res. 2012; 27(10): 2223-2230, doi: 10.1002/jbmr.1648, indexed in Pubmed: 22549969.

47. Romagnoli E, Cipriani C, Nofroni I, et al. „Trabecular Bone Score” (TBS): an indirect measure of bone micro-architecture in postmenopausal patients with primary hyperparathyroidism. Bone. 2013; 53(1): 154-159, doi: 10.1016/j.bone.2012.11.041, indexed in Pubmed: 23228370

48. Díaz-Soto G, de Luis Román D, Jauregui OI, et al. Trabecular Bone Score in Patients With Normocalcemic Hyperparathyroidism. Endocr Pract. 2016; 22(6): 703-707, doi: 10.4158/EP151055.OR, indexed in Pubmed: 26866705.

49. Silva BC, Boutroy S, Zhang C, et al. Trabecular bone score (TBS) - a nove method to evaluate bone microarchitectural texture in patients with 
primary hyperparathyroidism. J Clin Endocrinol Metab. 2013; 98(5): 1963-1970, doi: 10.1210/jc.2012-4255, indexed in Pubmed: 23526463.

50. Walker MD, Saeed I, Lee JA, et al. Effect of concomitant vitamin D deficiency or insufficiency on lumbar spine volumetric bone mineral density and trabecular bone score in primary hyperparathyroidism. Osteoporos Int. 2016; 27(10): 3063-3071, doi: 10.1007/s00198-016-3637-0, indexed in Pubmed: 27198233.

51. Rolighed L, Rejnmark L, Sikjaer T, et al. Vitamin D treatment in primary hyperparathyroidism: a randomized placebo controlled trial. J Clin Endocrinol Metab. 2014; 99(3): 1072-1080, doi: 10.1210/jc.2013-3978, indexed in Pubmed: 24423366.

52. Hwangbo Y, Kim JH, Kim SW, et al. High-normal free thyroxine levels are associated with low trabecular bone scores in euthyroid postmenopausal women. Osteoporos Int. 2016; 27(2): 457-462, doi: 10.1007/s00198-015-3270-3, indexed in Pubmed: 26252978.

53. De Mingo Dominguez ML, Guadalix Iglesias S, Martin-Arriscado Arroba $\mathrm{C}$, et al. Low trabecular bone score in postmenopausal women with differentiated thyroid carcinoma after long-term TSH suppressive therapy. Endocrine. 2018; 62(1): 166-173, doi: 10.1007/s12020-018-1671-8, indexed in Pubmed: 30014437.

54. Moon JH, Kim KM, Oh TJ, et al. The Effect of TSH Suppression on Vertebral Trabecular Bone Scores in Patients With Differentiated Thyroid Carcinoma. J Clin Endocrinol Metab. 2017; 102(1): 78-85, doi: 10.1210/jc.2016-2740, indexed in Pubmed: 27754806.
55. Kužma M, Vaňuga P, Binkley N, et al. High Serum Fractalkine is Associated with Lower Trabecular Bone Score in Premenopausal Women with Graves' Disease. Horm Metab Res. 2018; 50(8): 609-614, doi: 10.1055/a-0633-2814, indexed in Pubmed: 29954010.

56. Poiana C, Capatina C. Fracture Risk Assessment in Patients With Diabetes Mellitus. J Clin Densitom. 2017; 20(3): 432-443, doi: 10.1016/j. jocd.2017.06.011, indexed in Pubmed: 28716499.

57. Neumann T, Lodes S, Kästner B, et al. Trabecular bone score in type 1 diabetes — a cross-sectional study. Osteoporos Int. 2016; 27(1): 127-133, doi: 10.1007/s00198-015-3222-y, indexed in Pubmed: 26187124

58. Dhaliwal R, Cibula D, Ghosh C, et al. Bone quality assessment in type 2 diabetes mellitus. Osteoporos Int. 2014; 25(7): 1969-1973, doi: 10.1007/s00198-014-2704-7, indexed in Pubmed: 24718377.

59. Kim JH, Choi HJ, Ku EuJ, et al. Trabecular bone score as an indicator for skeletal deterioration in diabetes. J Clin Endocrinol Metab. 2015; 100(2): 475-482, doi: 10.1210/jc.2014-2047, indexed in Pubmed: 25368976.

60. Leslie WD, Aubry-Rozier B, Lamy O, et al. Manitoba Bone Density Program. TBS (trabecular bone score) and diabetes-related fracture risk. J Clin Endocrinol Metab. 2013; 98(2): 602-609, doi: 10.1210/jc.2012-3118, indexed in Pubmed: 23341489.

61. Caffarelli C, Giambelluca A, Ghini V, et al. In Type-2 Diabetes Subjects Trabecular Bone Score is Better Associated with Carotid Intima-Media Thickness than BMD. Calcif Tissue Int. 2017; 101(4): 404-411, doi: 10.1007/s00223-017-0297-9, indexed in Pubmed: 28664329. 